\title{
The Power of Synergy: An Academic/Clinical Partnership for Transformational Change
}

\author{
Ann McKillop, ${ }^{1}$ Cheryl Atherfold, ${ }^{2}$ and Gary Lees ${ }^{3}$ \\ ${ }^{1}$ University of Auckland, Auckland 1142, New Zealand \\ ${ }^{2}$ Waikato District Health Board, Hamilton 3240, New Zealand \\ ${ }^{3}$ Lakes District Health Board, Rotorua 3023, New Zealand \\ Correspondence should be addressed to Ann McKillop; a.mckillop@auckland.ac.nz
}

Received 28 April 2014; Revised 6 August 2014; Accepted 9 August 2014; Published 20 August 2014

Academic Editor: Jenny M. Wilkinson

Copyright (C) 2014 Ann McKillop et al. This is an open access article distributed under the Creative Commons Attribution License, which permits unrestricted use, distribution, and reproduction in any medium, provided the original work is properly cited.

\begin{abstract}
Background. A programme of postgraduate study was developed in partnership between a health board and a university in New Zealand, having identified critical thinking and practice change as key determinants of good care delivery. Aim. To explore the impact after 12 months of a postgraduate programme for registered nurses on patient assessment and clinical reasoning, and the status of implementation plans for improved patient care. Design. Outcome evaluation using a survey and focus groups. Setting. On location at a hospital in a small city in New Zealand that provides healthcare services for 102,000 people across rural and urban areas. Participants. Registered nurses who had completed the programme $(N=28)$ and seven clinical mentors. Methods. A survey, focus groups, and follow-up data about quality improvement projects were used to explore how the programme was experienced and its impact. Results. The survey revealed perceptions of improved knowledge and skills but a lack of confidence in communicating with medical staff. Of 28 quality improvement projects planned, all but three had been implemented and were still in use. Two themes were generated from focus group data: "new ways of thinking" and "doing things differently." Conclusions. This academic/clinical partnership positively influenced nurses' knowledge and skills, encouraged critical thinking and self-efficacy, and resulted in the sustained implementation of nurse-initiated projects intended to improve patient care.
\end{abstract}

\section{Introduction}

As the context of nursing practice continues to increase in uncertainty, instability, and complexity, registered nurses are exposed regularly to situations that take them to the edge and at times beyond their current knowledge and skill base, putting on full stretch their resources to adapt and learn [1]. Therefore, appropriate support in this environment goes beyond that based on "thinned out" understandings of the clinical context and their work. Decisions about nurses' professional development needs that are made in isolation of an appreciation of the realities of practice can lead to excessive emphasis on performance, blame-seeking, insufficient attention to the complexity of practice, and a default to generic, technical education to fix problems [2]. Therefore, transformative learning in which registered nurses grow as critical thinkers and knowledge workers while also continuing to develop essential technical knowledge and skills is both a challenge and an essential goal for nursing education and for advancing nursing knowledge $[3,4]$.

\section{Tame and Wicked Problems}

The problems faced by nurses in everyday practice have been categorised as tame or wicked, based on the degree of difficulty in finding solutions and the mode of inquiry employed to address them [4]. This division was originally described by Rittel and Webber [5] and applied to the field of social planning but has been found appropriate to a range of professionals who work with issues and realties that are both straightforward and messy [6]. Problems are tame when solutions to them are well defined and already known and can be arrived at using steps of logic in the tradition of technical rationality. They are amenable to standard procedures that are expected to bring about usually permanent solutions [4]. 
Working with tame problems in healthcare is well suited to the application of evidence-based protocols and pathways, in which the same solutions can be applied in similar situations to achieve well-defined outcomes with a degree of certainty of effect [1]. Wicked problems, on the other hand, are multifaceted and complex and defy linear thinking, and their solutions (if any) are elusive, highly context-dependent, and likely to be impermanent [5]. Nurses working with wicked problems need to be able to draw on their ability to work things out on the spot, in a reflective dynamic of thought and action in which potential solutions are tried and tested aiming for a resolution that is not necessarily complete $[1,3,4,6]$. What is found to work in one situation is not expected to work in the same way in another similar situation. Active processing of wicked problems requires critical questioning of values, beliefs, taken-for-granted assumptions, and ways of working with self and others that provoke change $[3,4,6]$. The ever-changing interactions in which nurses engage with communities, healthcare consumers, technology/treatments, and other health professionals put them in the path of both tame and wicked problems, each requiring different forms of logic, knowledge, and skills. Therefore, the education that nurses require for their everyday practice supports their solution-finding of both tame and wicked problems.

Health care organisations are powerfully influential in determining the nature of professional development of nurses in their employ and, therefore, the expectations they have of the role of teaching and learning in workforce development are fundamental to the nature of what is funded and supported by them. An instrumental orientation by an organisation is centred on learning in the performative mode to correct identified deficits in the performance of competencies required of specific roles [6]. Such an orientation is resistant to challenging taken-for-granted assumptions and avoids risky or uncertain outcomes, in deference to action that will meet urgent tasks, targets, and deadlines [6], an approach that has been referred to as the hamster wheel of busyness [7]. A contrasting, intrinsic perspective, in which organisations adopt an approach to learning that values the holistic development and personal agency [8] of nurses, is foundational to tackling wicked problems, makes a valuable impact on tame problems, and supports transformational change [6, 9-11].

The literature concerning postgraduate education for registered nurses supports its impact on learning from an instrumental, technorational orientation, for example as the most appropriate preparation for advanced nursing practice roles [12-14]; and that a postgraduate nursing qualification has been associated with fewer medication errors, more effective triaging of patients, and overall improved clinical outcomes [15-17]. Further, postgraduate study is expected to enhance the implementation of evidence into practice $[18,19]$ and to increase nurses' confidence in their ability [20-24]. On the other hand from an intrinsic, critical perspective, nurses who have completed postgraduate education have also been found to be more likely to be critical thinkers [25] and advocates for patients by questioning treatment decisions and options [25-27], and to be supported to develop personally and professionally $[17,28,29]$.

\section{Background}

In this paper we present a limited evaluation at least 12 months after two cohorts of registered nurses completed a programme of postgraduate study developed in partnership between a district health board (DHB) and a university in New Zealand. The partners collaborated to build and deliver a curriculum that would support nurses in their work with both tame and wicked problems. Before the partners came together the DHB had developed a strategic nursing workforce development plan that guided the purchase of postgraduate education, funded by the New Zealand Ministry of Health to all DHBs and that was to be delivered by a university. The original intention of the DHB was to advance the capability of frontline nurses in assessment, diagnostic reasoning, critical thinking, and practice change. The curriculum for the programme was teased out in a series of conversations among senior nurses in the health service and university-based academics to agree the learning processes, content and delivery of two postgraduate courses for registered nurses that constituted a postgraduate certificate (equivalent to $25 \%$ of a Master degree) as a "bespoke, strategic reform package" [9]. Curriculum development using this approach is suitable for establishing threshold concepts, those that are critical to the development of nursing knowledge and practice [30], and to establish teaching approaches and methods that support transformational learning [31].

Threshold concepts are so named because once students pass through a threshold of knowledge and understanding about an issue into a new way of perceiving and working, they will never again be able to unknow what has become known $[30,32]$. Five features of threshold concepts are that they are usually transformative; not amenable to knowing in the same way that which has been previously known; are likely to involve discomfort in the transition to new knowledge and practice; and have the capacity to enable integration and application of bounded knowledge [31]. The importance of identifying threshold concepts early in planning the programme was to focus on the process of student learning rather than what has been recognised as a fundamental flaw that of content-building that leads to adding yet more content $[3]$.

The threshold concepts for the programme were identified through discussion between the partners. They included students adopting a sense of inquiry that breaks through the surface of daily routine and habits of mind; mindfulness and critical reflection on their personal values and beliefs and the differences that may exist about nursing and patient care in the clinical team; discovering needs for change and the part they need to play in effecting improvement; evidence-based patient assessment skills, clinical reasoning, and therapeutic actions that went beyond routine monitoring and treatment; and appreciation that long-term solutions to complex problems require integrated and collaborative teams that seek creative solutions and actions.

Discussion between the partners established that the underpinning principles (see Table 1) and methods for the delivery of the programme were to be based on practice development (PD) because of their potential to support 
Table 1: The Nine Principles of Practice Development [11].

(1) Aims to achieve person-centred and evidence based care that is manifested through human flourishing and a workplace culture of effectiveness in all healthcare settings and situations

(2) Directs attention at the micro-systems level-the level at which most healthcare is experienced and provided, but ensures coherent support from interrelated mezzo and macro-systems levels

(3) Integrates work-based learning with its focus on active learning and formal systems for enabling learning in the workplace

(4) Integrates and enables both the development of evidence from practice and the use of evidence in practice

(5) Integrates creativity with cognition in order to blend differing energies, enabling practitioners to free their thinking and allow opportunities for human flourishing to emerge

(6) A complex methodology that can be used across health care teams and interfaces to involve all internal and external stakeholders

(7) Uses key methods consistent with the methodological principles being operationalised and the contextual characteristics of the PD programme of work

(8) Utilises a set of processes including skilled facilitation that can be translated into a specific skill-set required as near to the interface of care as possible

(9) Integrates evaluation approaches that are always inclusive, participative and collaborative

transformative learning and influence change consistent with the threshold concepts identified for the programme. A review of the impacts of $\mathrm{PD}$ had identified a range of pertinent outcomes including changing workplace cultures so they are more person-centred, development of learning cultures, increased empowerment of staff, greater team capacity, frameworks to guide ongoing development, shared understanding of contributions within a team, and development of new approaches to care [33]. Additionally the accepted criteria for "good" PD, collaboration, inclusion, and participation (CIP) [34] were consistent with how students would be encouraged to engage in transformative ways with each other, educators, mentors, colleagues, and patients. Transformative learning is acknowledged as a process that engages students in critical questioning of routine practice, habits, and thinking; challenging taken-for-granted assumptions, beliefs, and values; realisation of the structures and processes that create the inequities of the status quo; and generating beliefs to guide action and contribute to change $[30,35]$. These ways of working are known to contribute to leadership ability, more effective workplace cultures, person-centredness, advancing skills in effecting change, and confidence in using inclusive, collaborative change processes [36-38].

\section{Delivery of the Programme}

The synergy of ideas and energy that grew the clinical/academic partnership during the planning stages of the programme had established a sound working relationship for the delivery of the programme. The two courses that comprised a postgraduate certificate were each one semester long: the first an already established course in the university's offerings and the second a course newly developed for the programme. The first course aimed to prepare students for finding solutions to tame problems with its focus on advancing knowledge and skill in client assessment, the ability to request, understand, and interpret diagnostic tests, and the use of findings from tests and physical examinations as the basis for evidence-based diagnostic reasoning and decisions about nursing care. However, because patients rarely manifest standard characteristics of health problems or unremarkable circumstances and often present with multiple coexisting problems, students were challenged throughout to reflect on their assumptions, logic, and impressions towards more wicked, person-centred assessment and reasoning in the context of the complexity of people's lives. Delivery of the first course was on site at the main hospital campus of the DHB over five study days. Even though this mode of delivery restricted teacher-student contact to taught sessions, transmission of content modes of teaching were mitigated through interaction and engagement with students that encouraged critical thinking $[3,4]$ in relation to the first and fourth principles of PD (see Table 1). Students contributed to the development of the programme for each day according to their learning needs.

The second course was a new course developed to specifically support students in transition through the threshold concepts of the programme that were developed into learning outcomes around the themes of person-centred care, critical thinking, leadership, effective workplace cultures, and transformational change. CIP principles were adopted in student engagement in fine-tuning the details of the sessions for five study days but also most importantly through work-based learning [36] which was a feature throughout the course. Each student engaged in partnerships with identified mentors (one academic and one clinical) to develop an individualized, practice-based learning contract that was to guide their journey of transformative learning. The mentors were prepared for their role in transformative learning through a precourse workshop and supported by course leaders during the course. Student-mentor partnerships were intended to support critical reflection in and on practice, progress toward learning outcomes, and development of work for summative assessments.

The principles of practice development were embedded in the learning experiences offered at the study days and in the way that academic and clinical mentors worked with students. PD principles (Table 2) were role-modelled and discussed throughout this course in study days and in mentoring relationships, and students were required to articulate the ways they had incorporated these principles into the summative assessments for the course, most comprehensively in a plan they submitted for transformational change based on multiple forms of evidence in their clinical workplace setting. It is beyond the scope of this paper to provide a comprehensive description of how each principle was specifically integrated. However, Table 2 provides some examples of how this was achieved. 
TABLE 2: Integration of practice development principles into programme.

\begin{tabular}{|c|c|}
\hline Practice development principles [11] & Examples of integration into programme \\
\hline $\begin{array}{l}\text { (1) Person-centred and evidence based care through } \\
\text { human flourishing in workplace culture of effectiveness }\end{array}$ & $\begin{array}{l}\text { Students engaged in critical reflection in and on their own practice; } \\
\text { articulated their thinking and actions in class, with mentors in } \\
\text { workplace and incorporated this principle in work submitted for } \\
\text { assessment. Evidence-based patient assessment and diagnosis was a } \\
\text { feature of the first course. }\end{array}$ \\
\hline $\begin{array}{l}\text { (2) Attention at the microsystems level with support } \\
\text { from mezzo and macro-systems levels develops }\end{array}$ & $\begin{array}{l}\text { Critical analysis required in plan for change through use of PARiHS } \\
\text { framework [39] to guide identification of barriers and enablers to } \\
\text { implementation of change. }\end{array}$ \\
\hline $\begin{array}{l}\text { (3) Work-based learning through active learning and } \\
\text { formal systems for enabling learning in the workplace }\end{array}$ & $\begin{array}{l}\text { Enabled as key feature of second course and addressed by students in } \\
\text { their plan for change. }\end{array}$ \\
\hline $\begin{array}{l}\text { (4) Development of evidence from practice and the use } \\
\text { of evidence in practice }\end{array}$ & $\begin{array}{l}\text { Use and generation of multiple forms of evidence recognised in } \\
\text { teaching/learning and summative assessments for both courses. }\end{array}$ \\
\hline $\begin{array}{l}\text { (5) Creativity with cognition to blend differing energies, } \\
\text { enable free-thinking and opportunities for human } \\
\text { flourishing }\end{array}$ & $\begin{array}{l}\text { Encouraged in students' development of self and others through class } \\
\text { discussion and summative assessments. }\end{array}$ \\
\hline $\begin{array}{l}\text { (6) Complex methodology used across health care } \\
\text { teams and interfaces involving internal and external } \\
\text { stakeholders }\end{array}$ & $\begin{array}{l}\text { Acknowledged in class discussion and "unpacking" encouraged with } \\
\text { mentors. }\end{array}$ \\
\hline $\begin{array}{l}\text { (7) Methods consistent with the principles being } \\
\text { operationalised and context of the PD work }\end{array}$ & $\begin{array}{l}\text { Teaching methods used and students' plans for implementing } \\
\text { transformational change were intended to be consistent with PD } \\
\text { principles. }\end{array}$ \\
\hline $\begin{array}{l}\text { (8) Includes skilled facilitation as near to the interface } \\
\text { of care as possible }\end{array}$ & $\begin{array}{l}\text { Facilitation was role-modelled in teaching/learning sessions and } \\
\text { expected to be reflected in plans for implementing change. }\end{array}$ \\
\hline $\begin{array}{l}\text { (9) Evaluation that is inclusive, participative, and } \\
\text { collaborative }\end{array}$ & $\begin{array}{l}\text { Students, clinical staff, mentors and academics engaged in informal } \\
\text { evaluation of the programme that modified its delivery as much as } \\
\text { possible. Students formally evaluated the course at its completion using } \\
\text { usual university processes. Students incorporated CIP principles into the } \\
\text { evaluation section of their plans for change. }\end{array}$ \\
\hline
\end{tabular}

Informal and formal evaluations of the programme of education were conducted throughout and at the end of both courses that made up the postgraduate certificate. However, the longer term impact of the programme as a whole from the perspectives of nurses and their clinical mentors who participated and the outcomes of the plans for change in their workplaces had not been evaluated. Therefore the following sections report on a limited evaluation that aimed to explore the impact after 12 months of a postgraduate programme for registered nurses on patient assessment and clinical reasoning and the status of implementation of a plan for improved patient care.

\section{Participants}

Participants included two cohorts of registered nurses who had completed the postgraduate certificate, 13 nurses in 2010 and 15 in 2011, along with seven nurse mentors who had worked one-on-one with students assisting with the application of learning into clinical practice.

\section{Setting}

The evaluation was conducted on location at the District Health Board premises of the clinical partner in this programme. This facility is set in a small city in New Zealand and provides healthcare services for 102,000 people living in the surrounding region.

\section{Methods}

A survey, two focus groups, and follow-up data concerning the quality improvement projects were accessed to gain insight into how the programme was experienced and its impact on nurses' patient assessment, clinical reasoning, and the status of the plans they had made for change in their clinical areas. The limitations of the survey in regard to the CIP principles that had underpinned the delivery of the second course taught 12-18 months previously is acknowledged. However over that time many of the nurses had moved from their original place of work and were less available for the more collaborative, inclusive and participative processes that had been adopted during programme delivery. The survey instrument had been previously validated to ascertain learners' perceptions of the impact of postgraduate education and the items included were deemed relevant to the aim of this evaluation [24]. Focus groups were held to illuminate the perceptions of nurses and mentors after completion of the programme. The status of implementation of the plans for change that had been submitted for coursework assessment was requested from the programme graduates and/or the relevant clinical areas, 18 months after the programme for the 2010 cohort and after 12 months for the 2011 cohort. 
TABLE 3: Focus group topics.

Relevance of course content to everyday clinical practice

Opportunities to practice what had been taught

Development of clinical decision-making ability and how this was evident or not

Most valuable supports to putting new learning into practice Most obvious challenges to putting new learning into practice

Ethical approval was obtained from the Ethics Committees of the healthcare institution and the NZ Ministry of Health. All participants received information sheets prior to being asked for their written consent to participate. Ethical principles were adhered to throughout, including confidentiality being agreed to in the focus groups, deidentification of data, and information about how to withdraw from the study, if desired.

7.1. Survey. A hard-copy of the questionnaire was sent out to participants and returned by internal post to an administrator. The survey included brief demographic details and participants were asked to use a five-point Likert scale to rank their level of agreement on forty-seven statements in seven sections: knowledge and understanding, application of knowledge and critical thinking, impact on patients care, communication and sharing knowledge in the workplace, workplace activities, and ongoing professional development. Twenty-one anonymously completed survey forms were returned of 29 distributed ( $72 \%$ return rate). Data were entered into Excel and subjected to descriptive analysis.

7.2. Focus Groups. Two focus groups were convened: one of two mentors and the other included five programme participants, representative of each student cohort. The aim of the focus groups was to explore nurses and mentors experiences of applying the learning from study days into clinical practice. Focus groups were held at mutually agreed, convenient venues as close to participant's work settings as possible and where people were most likely to engage in candid discussion. One of the researchers facilitated both groups, encouraging all points of view, and asking openended questions. These were audio recorded and transcribed verbatim. A topic list for focus groups is presented in Table 3

7.3. Qualitative Data Analysis. Qualitative data were analysed thematically using content analysis that involved five steps: familiarisation, identifying a thematic framework, indexing, charting, mapping, and interpretation [40]. Two authors undertook the first three steps independently, resulting in transcripts annotated with codes named to represent content. We conferred and reached agreement on coding, independently aggregated codes into categories, and conferred to achieve consensus. All codes for each category were checked and rechecked using constant comparison [41]. The final stage of data analysis involved refining and defining the allocation of categories to provisional themes until we were satisfied that the themes could be tracked back to transcripts. Member checking was achieved by provisional themes being communicated to participants for them to comment on whether they made sense to them in terms of their experience. No contrary comments were received. Brief details of the quality initiatives were sorted into tables for each cohort of participants.

\section{Findings}

8.1. Practice Development Projects. With support from a clinical and an academic mentor, participants submitted a comprehensive plan for implementing evidence into practice that would address an issue of concern identified collaboratively with colleagues from their practice setting. The plan provided details of how practice development methods would be used (to address barriers and supports identified through use of the PARIHS framework [39]) through each step of implementation. Table 4 indicates the nature of the 28 projects and follow-up with course participants and/or clinical areas 1218 months following completion of the programme revealed that all, except three, were fully implemented and continued to be used in practice. The projects are described in Table 4 .

8.2. Survey Findings. There were 21 completed surveys returned of 29 distributed (72\%), eight from the 2010 cohort of 12 distributed, six from the 2011 cohort of 10 distributed, and all mentors (7) completed and returned the questionnaire. As in Table 5, mentor respondents were all registered as nurses more than 10 years ago and all but one had more than 10 years' experience in their specialty. Respondents undertaking the programme mostly had more than 10 years since registration and less time overall in their specialties when compared to mentors.

Respondents indicated their level of agreement to the statements (Table 6) on a scale of one (strongly disagree) to five (strongly agree). Mentors responded in terms of how they thought the programme impacted on their mentees and course participants answered according to impact on self. All except two items were scored over 3.0. Areas of strongest agreement $(+/=4.5)$ were in relation to improved knowledge about patient assessment, clinical skills, comprehensive view of patients, requests to fulfil a teaching role, being asked for advice, innovative practice, and enhanced career options. The strongest disagreement was about confidence in communicating with medical staff (mean score 2.0) and perception of being respected in the workplace (mean score 2.1), even though their qualifications were valued (4.5).

8.3. Focus Group Findings. The data from focus groups indicated how the programme had impacted on nurses' practice in two important ways that emerged as dominant themes, "new ways of thinking" and "doing things differently." Nurses spoke freely about their own (or their mentees') practice since undertaking the programme. The first theme described how the programme had stimulated changes in thinking and learning from practice, making decisions, and working with colleagues. The second theme concerned change in practice including increased confidence, addressing challenges, and drawing on a stronger knowledge base.

New Ways of Thinking. Nurses and mentors spoke about how to think differently so that they "got a win out of it" but there was an uncomfortable learning curve that challenged them 
TABle 4: Practice development projects.

\begin{tabular}{lll}
\hline Purpose of projects & Topics & Implementation status \\
\hline $\begin{array}{l}\text { Development of } \\
\text { evidence-based resources } \\
\text { to inform practice }(n=5)\end{array}$ & $\begin{array}{l}\text { Urology theatre procedures, cardiac pacing, } \\
\text { Cardio-pulmonary resuscitation education, neurovascular } \\
\text { observations and oral hygiene for critically ill patients. }\end{array}$ & $\begin{array}{l}\text { Three fully implemented } \\
\text { recommendations for the other two } \\
\text { being incorporated into wider } \\
\text { reviews. }\end{array}$ \\
\hline
\end{tabular}

Placement of nasogastric tube in children, withdrawal of use of promethazine in chemotherapy unit, humidification during artificial ventilation, falls prevention in surgical unit, falls risk assessment, use of Heliox for acute asthma (ICU), nurse-led assessment of foot problems in diabetic patients, assessment of venous leg ulcers, assessment of unilateral

Evidence-based changes in practice $(n=17)$

headache (walk-in nurse clinic), assessment and treatment of uncomplicated urinary tract infection (walk-in nurse clinic), oxygen administration in children, prevention of venous thromboembolism, recording ECG, education of inhaler techniques, procedure for CAPD, post-operative nausea and vomiting, nurse-led clinic for diabetic patients in general practice.

\begin{tabular}{lll}
\hline $\begin{array}{l}\text { Audit and feedback with } \\
\text { follow-up actions using } \\
\text { practice development } \\
\text { methods }(n=4)\end{array}$ & $\begin{array}{l}\text { Hand hygiene, use of BiPAP, refrigerated storage of } \\
\text { medicines, constipation in older person health. }\end{array}$ & $\begin{array}{l}\text { Three initiatives implemented and } \\
\text { ongoing improvement continues. } \\
\text { The recommendation for one } \\
\text { project is yet to be implemented. }\end{array}$ \\
\hline $\begin{array}{l}\text { Information/education } \\
\text { resources for patients } \\
(n=2)\end{array}$ & $\begin{array}{l}\text { Education for patients booked for elective cardioversion and } \\
\text { a resource to support home management of gastro-enteritis } \\
\text { following discharge from Emergency Department. }\end{array}$ & Both fully implemented. \\
\hline
\end{tabular}

TABLE 5: Characteristics of survey respondents.

\begin{tabular}{llcc}
\hline Survey respondents & Clinical specialty & Years since registration as nurse & Years in current service \\
\hline Mentors $(n=7)$ & $\begin{array}{l}\text { Acute medical/surgical wards and a small } \\
\text { regional hospital }\end{array}$ & All $>10$ years & $\begin{array}{c}6 \times>10 \mathrm{yrs} \\
1 \times 5-10 \mathrm{yrs}\end{array}$ \\
\hline $\begin{array}{l}\text { Nurses in } 2010 \text { cohort } \\
(n=8)\end{array}$ & $\begin{array}{l}\text { Perioperative, ICU, oncology and } \\
\text { continuing education }\end{array}$ & $\begin{array}{c}7 \times>10 \mathrm{yrs} \\
1 \times 5-10 \mathrm{yrs}\end{array}$ & $\begin{array}{c}5 \times>10 \mathrm{yrs} \\
5-10 \mathrm{yrs} \\
1 \times<5 \mathrm{yrs}\end{array}$ \\
\hline $\begin{array}{l}\text { Nurses in 2011 cohort } \\
(n=6)\end{array}$ & ICU and medical nursing & $\begin{array}{l}5 \times>10 \mathrm{yrs} \\
1 \times<5 \mathrm{yrs}\end{array}$ & $\begin{array}{c}1 \times>10 \mathrm{yrs} \\
2 \times 5-10 \mathrm{yrs} \\
3 \times<5 \mathrm{yrs}\end{array}$ \\
\hline
\end{tabular}

to unpack how they thought about their work and stretched them intellectually.

8.3.1. Got a Win Out of It. There was a positive impact on learning, practice, and teamwork. For one nurse, the win she experienced from the programme was not just for her but for the team who worked with her on a project and later for the whole organization as the change in practice was scaled up.

"Something that I hadn't expected was that it validated the work we were all doing...in terms of falls prevention. So they (other nurses) kind of got a win out of it too because I didn't do the work; they did the work; and from that we have a change in practice that was so phenomenal, it ended up going organization-wide." (Participant 2).

For another participant the gains about the direct relevance to her practice because she decided the focus of her learning: "The self-directed learning and that project that I did was really relevant and I think I learnt a lot from that and I do use it in every day practice. I have found it extremely relevant yeah" (Participant 1 ). The positive impact was obvious to another nurse due to the learning experiences offered. She commented, "The 2nd paper (course) it was really really good because that had definite impact on my practice and I just loved it and it was just kinda me" (Participant 4). For one of the mentors, the solution-focused approach to practice change enabled participants to advance good ideas into action, "Practice development is actually a good way of doing it...definitely. Sometimes people (used to) have good ideas and we couldn't take it further and that's hard" (Mentor 2).

Finally, another mentor interpreted the win in terms of ongoing skill development, "It's the know-how and the know-why that I think condenses and increases skills. Some people increased their skills considerably and then negotiated to continue doing that" (Mentor 1). 
TABLE 6: Nurses' perceptions of the impact of the programme.

\begin{tabular}{|c|c|}
\hline & Mean score* \\
\hline \multicolumn{2}{|l|}{ Knowledge and understanding: } \\
\hline Knowledge base is sufficient for my role & 4.1 \\
\hline Understanding of the pathophysiology of common conditions I encounter & 4.1 \\
\hline Understanding of disease processes & 4.3 \\
\hline Understanding of biological sciences & 4.0 \\
\hline Knowledge relevant to patient assessment & 4.8 \\
\hline \multicolumn{2}{|l|}{ Application of knowledge: } \\
\hline Confidence in carrying out technical procedures & 4.3 \\
\hline Understanding of the information from diagnostic tests & 4.2 \\
\hline I order diagnostic tests appropriately for my patients & 3.8 \\
\hline I can interpret diagnostic information & 3.9 \\
\hline I use data from diagnostic tests to plan patient care & 4.0 \\
\hline My clinical skills would improve by undertaking postgraduate education & 4.5 \\
\hline \multicolumn{2}{|l|}{ Critical thinking: } \\
\hline I have a comprehensive view of my clients/patients & 4.5 \\
\hline I have strong analytical skills & 4.2 \\
\hline I tend to question my own patient care & 4.0 \\
\hline I tend to question the patient care of others & 3.9 \\
\hline I am skilled in evaluating research & 3.9 \\
\hline I consider the evidence behind practice frequently & 3.4 \\
\hline My clinical decision making skills are obvious to me & 4.0 \\
\hline I am able to implement change in a clinical context & 4.0 \\
\hline \multicolumn{2}{|l|}{ Impact on patient care: } \\
\hline I believe my education has positively impacted on patient outcomes & 3.8 \\
\hline I am better able to explain to patients about their care & 4.2 \\
\hline I am more confident talking to patients and families about their care & 4.1 \\
\hline I pick up on my patients' problems sooner & 4.1 \\
\hline I am better at evaluating underlying causes for patient problems & 4.2 \\
\hline${ }^{* *}$ I have not had the opportunity to apply what I have learnt in postgraduate study in my workplace & 4.1 \\
\hline \multicolumn{2}{|l|}{ Communication and sharing knowledge in the workplace: } \\
\hline I am confident in communicating with medical staff & 2.0 \\
\hline I am requested often to fulfil a teaching role & 4.5 \\
\hline I teach junior staff effectively & 3.8 \\
\hline I am confident speaking at team meetings & 3.8 \\
\hline I am confident discussing research with colleagues & 3.7 \\
\hline I am comfortable having others observe my clinical skills & 3.7 \\
\hline I am likely to share my knowledge with other colleagues in my workplace & 4.1 \\
\hline Other staff members come to me for advice & 4.5 \\
\hline \multicolumn{2}{|l|}{ Workplace activities: } \\
\hline My patient notes are focussed and informative & 3.9 \\
\hline I am confident in coping with emergency situations & 4.2 \\
\hline I am innovative in my practice & 4.5 \\
\hline${ }^{* *}$ My colleagues feel threatened due to my qualifications & 3.9 \\
\hline I am respected in the workplace & 2.1 \\
\hline I am confident advocating for patients & 4.0 \\
\hline
\end{tabular}


TABLE 6: Continued.

Professional development:
I am keen to further my study
Further study would have a positive impact on my career
Further study would extend my career options
Further study would increase my eligibility for promotion
Further study would increase satisfaction with my work
Further study would increase my clinical responsibility
My qualifications are valued in my workplace
*items scored on a scale of 1-5 in which 1 strongly disagree, $5=$ stron
response.
8.3.2. On a Learning Curve. "High challenge/high suppor
(Titchens and McGinley 2003) approaches to learning
encouraged thinking critically about sustainable change
complex contexts. Nurses' comments about being
learning curve showed how they had been stretched. For
participant:
"(The first course) was such a learning curve it was
a completely different environment and I thought
it was really excellent for me. It was just fantastic
and I loved it to bits. The 2nd paper (course)
I hated but I have to say because you have to
think and stuff and it did my head in; but it has
encouraged me to reflect and the whole critical
thinking thing" (Participant 2 ).

Another nurse realised that she had lacked the assessment skills and knowledge she needed: "I thought the 1st paper (course) the assessment paper (course) was great 'cause I had been (in an acute care unit) for a couple of years and...I had really no assessment knowledge.... I hadn't done it...hadn't really covered it. . hadn't really learnt how to do that" (Participant 4).

Mentors were tasked with facilitating engagement with and motivating clinicians to work together on practice changes. As one mentor found, the learning curve for mentees involved "shifting their thinking; they actually start to think about how it fits with clinical reasoning and the framework starts to take shape" (Mentor 1).

8.3.3. Reflecting on Practice. Participant's comments indicated that reflecting on practice advanced learning in various ways. One of the mentors commented that reflection is "extremely relevant, it sort of just makes..., gives you the opportunity to stop and look, look forward, look back, everything really; it does make you stop and think about it" (Mentor 1) and a participant found that reflection enabled her to "go back and add and continue adding, building those layers once you have the basics" (Participant 3). Another participant found that critical reflection both rewarded and challenged as she had to "look at the whole evidence based critical thinking thing which I had never...., (I'm) really embarrassed. I think it's great; it's what you do in life and it's been a real eye opener for me, the whole reflective thing and practice development; it's all new; it's all a stretch and I really like it a lot" (Participant 4).

Participants were required to access and interpret literature and then to make connections to their practice and reach conclusions about changes required. One participant stated, "I suppose it was what I needed to push me into doing some reflection and some short case studies and to look back over things. It challenged me to reflect, as its easy not to do that as an ongoing thing. I think the amount of reading that is relevant to your practice pushes or encourages me to create changes my practice" (Participant 1). Reflection was found for another to "take away that rush of clinical practice and made me stand aside from that and read and look and push boundaries a little bit more" (Participant 1).

Doing Things Differently. Participants spoke about how they had come to practice differently and to challenge themselves and others. Participants' comments about doing things differently were linked to meeting the challenges associated with gaining self-confidence.

8.3.4. Meeting Challenges. One nurse said she got a "mental kick" from the programme, acknowledging that she needed to move away from doing things out of habit:

\section{"I needed the mental kick. I do feel like I forget a lot and I need to go back over it. I don't know if it's my vintage or whatever or I am a bit overloaded when it all comes on" (Participant 4).}

Another challenge was in being questioned in ways and about aspects of practice that they had not been used to: "It can be a harsh environment at times, being questioned" (Mentor 1). The requirement to identify barriers to practice change was also seen as meeting challenges ahead: "For any change there are going to be enablers or barriers. If you don't identify the barriers you will have issues" (Mentor 2).

8.3.5. Practicing in a Different Way. For one nurse, the change in practice was global: "I think the whole paper [course] just changed how I practice and I was just thinking about it as you were talking that I don't think I realised that" (Participant 4). For another, practice change was more about using different 
skills based on growth in knowledge: "The skills I learnt I do use in everyday practice and I do practice in a different way just because of what I did to broaden my knowledge" (Participant 1). There was also a realisation of more advanced practice, "Even just yesterday I was looking at something and thinking through what I have learnt. Then the doctor comes along and says exactly what I am thinking; wahoo I rock! Definitely makes me think a lot more" (Participant 5). One mentor viewed the changes in practice to involve advanced assessment skills and ways of processing knowledge and information, "They're taking on board things that have probably been something that they have not necessarily seen as a nursing skill" (Mentor 2).

8.3.6. Gaining Confidence. The learning gained through the programme was instrumental in developing participants' confidence and this was expressed as "the clinical assessment skill paper [course] built my confidence around some of the things I used to do years ago without even thinking about it" (Participant 3); and, "You felt more confident to go for it. Cause I think even in my position I think you feel more confident to look at other things; push the boundaries" (Participant 1).

Finally, one of the mentors found that the programme helped learners to have confidence not only in what they did know but also to admit to and be open to resolving what they were unsure of: "It's also having the confidence to present what you have found or what you can't see. I suppose it's knowing that you cannot only say I heard this and I saw that; it's also to be able to say but I am not quite sure.... Facilitates further learning because you might not be sure... it could be something new" (Mentor 2).

\section{Discussion and Conclusions}

The synergies made possible in an academic-clinical service partnership are illustrated in the findings of this evaluation. Hardy et al. (2013) emphasise the importance of such partnerships in work based education designed to advance practice performance in the support of practitioner-led innovation in complex and rapidly changing health care contexts [9]. The findings indicate that nurses advanced their ability to gather and understand information about their patients, to reflect and make sense of what they know, and then extrapolate what they discover about themselves, colleagues, and from patients to developing their nursing practice. The programme was geared towards them initiating and leading a process of change that would affect not only their own practice but that of others in the team and this was demonstrated through the practice development projects being fully implemented in wards and units and in some cases being scaled up across the hospital. The results indicate that nurses grasped the complexity of implementing change as wicked rather than tame and that they developed new ways of thinking and acting.

There are clear limitations of this study including the small size of the sample and the particular locality of the setting. The context of the development and delivery of the programme were such that the same outcome may not occur again elsewhere. Further limitations include that the data did not capture the complexity of transformational change in workplace cultures. However this would have perhaps been overambitious for the scope of this evaluation 12 to $18 \mathrm{mths}$ after small scale projects. Further, changes that participants reported they had experienced in their own practice and habits of mind must be viewed with caution in terms of how their impressions affect their actions in the long term.

However, there is some support in the data that ways of working consistent with the principles of practice development are known to contribute to leadership ability, personcentredness, advancing skills in effecting change, and confidence in using inclusive, collaborative change processes, although not for capturing the complex nature of more effective workplace cultures [36-38]. Items in the survey, for example, those, referring to being more likely to share knowledge, speak at meetings and being asked for advice suggest improved confidence, and in the focus groups comments that leading a project from which others got a win would indicate improved leadership abilities. The status of implementation of practice development projects would suggest that participants gained confidence and ability in effecting change and in using inclusive and collaborative change processes, as these were the criteria required in the plans submitted for assessment and there was no indication that the processes planned were not implemented. The limitation of this evaluation to capture change in workplace culture has been acknowledged above and the difficulty of such an endeavor is noted elsewhere [34].

However, the survey findings of a lack of confidence in communicating with medical staff and also lack of respect that they experienced in the workplace are contrary to the focus group findings and to the findings of other researchers who have found instead that collaboration and communication may be improved through postgraduate education [19, $27,28,42-45]$. This finding is of real concern not only because patients of health professionals that work well together suffer lower mortality rates [46] but that the positive impact of such a culture on teamwork and healthcare effectiveness [10] may have been underrealised in the study setting. This is an aspect of the practice environment that needs to be actively and skillfully addressed by professional leaders of health care teams in the organization.

A focus on creative solution-finding as opposed to reactive problem-solving was a feature of the second component of the programme to reorient thinking from ways that nurses have traditionally been taught [9]. Such tame thinking is more likely to perpetuate difficulties and result in the neglect of important opportunities for change rather than the viewpoints and puzzling that leads to solution creation regarding wicked problems $[9,47]$. Such a reorientation works to direct attention to what is going right, not just what is going wrong, in order to build on strengths, achievements, and capacity [48]. The findings indicate nurses were enabled and empowered to achieve a more advanced level practice in ways that Hardy et al. (2013) [9] consider are likely to capture creative energy.

Everyday practice can easily become unconsciously routine as people work together and individually act the same way in familiar circumstances [49]. Breaking away from 
what has become customary is likely to trigger discomfort and to take energy and focus that can be difficult to muster in a busy, complex environment. The programme provided opportunities to disengage from the "hamsterwheel of busyness" [38] and to engage in learning from experience. The results show that participants had grown in confidence through the course and were thinking differently about their practice. Firstly, they were able to turn thought back on action, becoming aware of what they were doing, and secondly, how they were doing it so that practice-based knowledge was underpinning their practice [50]. Critical reflection underpinned their ability to identify and challenge barriers to practice innovation and to recognise how social structures and assumption-based practices impacted on the thinking and behavior of themselves and others [51].

The findings of this limited evaluation suggest that this particular academic/clinical partnership positively influenced nurses' knowledge and skills, encouraged critical thinking, and resulted in several sustained improvements in the quality of care. It is unlikely that a programme involving only one of the partners would have facilitated the personal and professional growth suggested by the results. The gains achieved through collaboration in all stages of development, delivery, and evaluation of the programme suggest the potential synergy to be achieved in clinicalacademic educational partnerships.

\section{Conflict of Interests}

The authors declare that there is no conflict of interests regarding the publication of this paper.

\section{References}

[1] T. Britt Pipe, "Preparing the emerging nursing and health care workforce: a case study," Nursing Administration Quarterly, vol. 38, no. 2, pp. 120-127, 2014.

[2] S. Nairn, "Social structure and nursing research," Nursing Philosophy, vol. 10, no. 3, pp. 191-202, 2009.

[3] M. McAllister, "STAR: a transformative learning framework for nurse educators," Journal of Transformative Education, vol. 9, no. 1, pp. 42-58, 2011.

[4] G. Rolfe, "Rethinking reflective education: what would Dewey have done?" Nurse Education Today, vol. 34, no. 8, pp. 1179-1183, 2014.

[5] H. W. J. Rittel and M. M. Webber, "Dilemmas in a general theory of planning," Policy Sciences, vol. 4, no. 2, pp. 155-169, 1973.

[6] J. Edmonstone, "On the nature of problems in action learning," Action Learning: Research and Practice, vol. 11, no. 1, pp. 25-41, 2014.

[7] K. Manley, “'The way things are done around here'-Developing a culture of effectiveness: a pre-requisite to individual and team effectiveness in critical care," Australian Critical Care, vol. 21, no. 2, pp. 83-85, 2008.

[8] A. Bandura, "Toward a psychology of human agency," Perspectives on Psychological Science, vol. 1, no. 2, pp. 164-180, 2006.

[9] S. Hardy, C. Jackson, J. Webster, and K. Manley, "Educating advanced level practice within complex health care workplace environments through transformational practice development," Nurse Education Today, vol. 33, no. 10, pp. 1099-1103, 2013.
[10] K. Manley, "Transformational culture: a culture of effectiveness," in Practice Development in Nursing, pp. 51-82, Blackwell, 2008.

[11] B. Mccormack, J. Dewing, L. Breslin et al., "Practice development: realising active learning for sustainable change," Contemporary Nurse A, vol. 32, no. 1-2, pp. 92-104, 2009.

[12] L. M. Aitken, J. Currey, A. P. Marshall, and D. Elliott, "Discrimination of educational outcomes between differing levels of critical care programmes by selected stakeholders in Australia: a mixed-method approach," Intensive and Critical Care Nursing, vol. 24, no. 2, pp. 68-77, 2008.

[13] L. Currie and L. Watterson, "Investigating the role and impact of expert nurses." The British Journal of Nursing, vol. 18, no. 13, pp. 816-824, 2009.

[14] J. Wilson-Barnett, "Continuing challenges for nursing in higher education," Journal of Advanced Nursing, vol. 3, no. 3, pp. 219220, 2006.

[15] L. H. Aiken, S. P. Clarke, R. B. Cheung, D. M. Sloane, and J. H. Silber, "Educational levels of hospital nurses and surgical patient mortality," Journal of the American Medical Association, vol. 290, no. 12, pp. 1617-1623, 2003.

[16] J. Considine, L. Ung, and S. Thomas, "Clinical decisions using the National triage scale: how important is postgraduate education," Accident and Emergency Nursing, vol. 9, no. 2, pp. 101-108, 2001.

[17] C. L. Covell, "Outcomes achieved from organizational investment in nursing continuing professional development," The Journal of Nursing Administration, vol. 39, no. 10, pp. 438-443, 2009.

[18] C. Bennison, "Emergency nurses' preceptions of the impact of post graduate education on their practice in New Zealand," in Nursing, p. 158, University of Otago, Dunedin, New Zealand, 2008.

[19] C. E. Cragg and M. Andrusyszyn, “Outcomes of Master's education in nursing," International Journal of Nursing Education Scholarship, vol. 1, no. 1, article 18, 2004.

[20] L. Clark, "Degrees of confidence," Nursing Older People, vol. 21, no. 2, pp. 23-25, 2009.

[21] B. Landmark, A. Wahl, and A. Bøhler, "Competence development in palliative care in Norway: a description and evaluation of a postgraduate education program in palliative care in Drammen, Norway," Palliative \& Supportive Care, vol. 2, no. 2, pp. 157-162, 2004.

[22] S. Walker, "Extolling the benefits of postgraduate education," Kai Tiaki Nursing New Zealand, vol. 15, no. 10, pp. 16-18, 2009.

[23] S. L. Tame, "The effect of continuing professional education on perioperative nurses' relationships with medical staff: findings from a qualitative study," Journal of Advanced Nursing, vol. 69, no. 4, pp. 817-827, 2013.

[24] D. Barnhill, A. McKillop, and C. Aspinall, "The impact of postgraduate education on registered nurses working in acute care," Nursing Praxis in New Zealand, vol. 28, no. 2, pp. 27-36, 2012.

[25] D. Pelletier, J. Donoghue, and C. Duffield, “Australian nurses' perception of the impact of their postgraduate studies on their patient care activities," Nurse Education Today, vol. 23, no. 6, pp. 434-442, 2003.

[26] S. Wildman, A. Weale, C. Rodney, and J. Pritchard, "The impact of higher education for post-registration nurses on their subsequent clinical practice: an exploration of students' views," Journal of Advanced Nursing, vol. 29, no. 1, pp. 246-253, 1999. 
[27] E. Williamson and M. Horsburgh, Evaluation of the Graduate Clinical Nursing Courses at the University of Auckland, University of Auckland, 2000.

[28] M. C. Cooley, "Nurses' motivations for studying third level postregistration nursing programmes and the effects of studying on their personal and work lives," Nurse Education Today, vol. 28, no. 5, pp. 588-594, 2008.

[29] J. Drennan, "Professional and academic destination of masters in nursing graduates: a national survey," Nurse Education Today, vol. 28 , no. 6 , pp. 751-759, 2008.

[30] M. McAllister, "Challenges facing nursing education in Australia: two solutions," Journal of Nursing Education and Practice, vol. 2, no. 1, pp. 20-27, 2012.

[31] S. Barradell, "The identification of threshold concepts: a review of theoretical complexities and methodological challenges," Higher Education, vol. 65, no. 2, pp. 265-276, 2013.

[32] J. Meyer and R. Land, "Threshold concepts and troublesome knowledge: linkages to ways of thinking and practising within the disciplines," ETL Project Occasional Report 4, Edinburgh, UK, 2003.

[33] B. McCormack and J. Wright, "A realist synthesis of evidence relating to practice development: findings from the literature analysis," Practice Development in Health Care, vol. 6, no. 1, pp. 25-55, 2007.

[34] B. McCormack, "Advancing the practice development outcomes agenda within multiple contexts," International Practice Development Journal, vol. 1, no. 4, 2011.

[35] J. Mezirow, Learning as Transformation, Jossey-Bass, San Francisco, Calif, USA, 2000.

[36] J. Dewing, "Moments of movement: active Learning and practice development," Nurse Education in Practice, vol. 10, no. 1, pp. 22-26, 2010.

[37] B. McCormack, J. Dewing, and T. McCance, "Developing person-centred care: addressing contextual challenges through practice development," The Online Journal of Issues in Nursing, vol. 16, no. 2, article 3, 2011.

[38] B. McCormack, K. Manley, and A. Titchen, Practice Development in Nursing and Healthcare, Wiley-Blackwell, Oxford, UK, 2nd edition, 2013.

[39] J. Rycroft-Malone, "The PARIHS framework: a framework for guiding the implementation of evidence-based practice," Journal of Nursing Care Quality, vol. 19, no. 4, pp. 297-304, 2004.

[40] C. Pope, S. Ziebland, and N. Mays, "Analysing qualitative data," British Medical Journal, vol. 320, no. 7227, pp. 114-116, 2000.

[41] N. Mays and C. Pope, "Rigour and qualitative research," British Medical Journal, vol. 311, no. 6997, pp. 109-112, 1995.

[42] D. F. Bell, E. Pestka, and D. Forsyth, "Outcome evaluation: does continuing education make a difference?" The Journal of Continuing Education in Nursing, vol. 38, no. 4, pp. 185-190, 2007.

[43] K. Caldwell, "Postgraduate education for nurses: the Middlesex model," Nurse Education Today, vol. 21, no. 3, pp. 218-224, 2001.

[44] S. Pullon and B. Fry, "Interprofessional postgraduate education in primary health care: is it making a difference?" Journal of Interprofessional Care, vol. 19, no. 6, pp. 569-578, 2005.

[45] D. Spence, "Advancing nursing practice through postgraduate education (part one)," Nursing Praxis in New Zealand, vol. 20, no. 2, pp. 46-55, 2004.

[46] C. Schmalenberg and M. Kramer, "Nurse-physician relationships in hospitals: 20,000 nurses tell their story," Critical Care Nurse, vol. 29, no. 1, pp. 74-83, 2009.
[47] K. Walsh, C. Moss, and M. Fitzgerald, "Solution focused approaches and their relevance to practice development," Practice Development in Health Care, vol. 5, no. 3, pp. 145-155, 2006.

[48] M. McAllister, L. Venturato, A. Johnston, J. Rowe, M. Tower, and W. Moyle, "Solution focused teaching: a transformative approach to teaching nursing," International Journal of Nursing Education Scholarship, vol. 3, article 5, no. 1, 2006.

[49] C. R. May, F. Mair, T. Finch et al., "Development of a theory of implementation and integration: Normalization Process Theory," Implementation Science, vol. 4, no. 1, article 29, 2009.

[50] G. Rolfe, D. Freshwater, and M. Jasper, Critical Reflection for Nursing and the Helping Professions, Palgrave, New York, NY, USA, 2001.

[51] N. Thompson and J. Pascal, "Developing critically reflective practice," Reflective Practice: International and Multidisciplinary Perspectives, vol. 13, no. 2, pp. 311-325, 2012. 


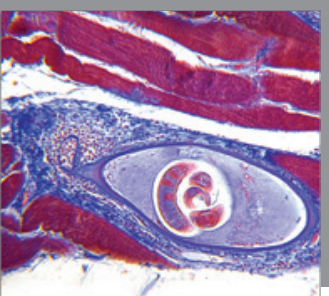

Gastroenterology

Research and Practice
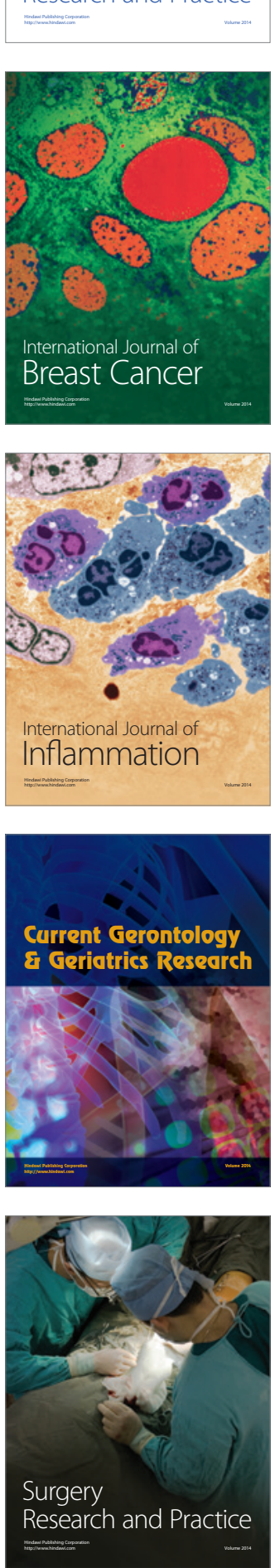

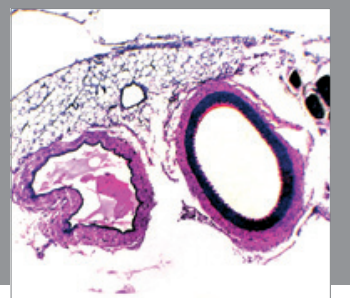

International Journal of Hypertension
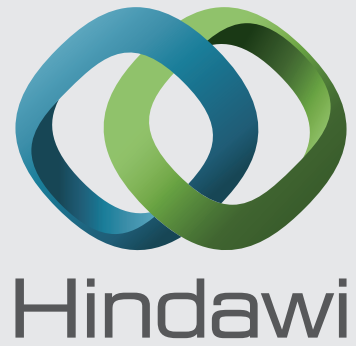

Submit your manuscripts at http://www.hindawi.com
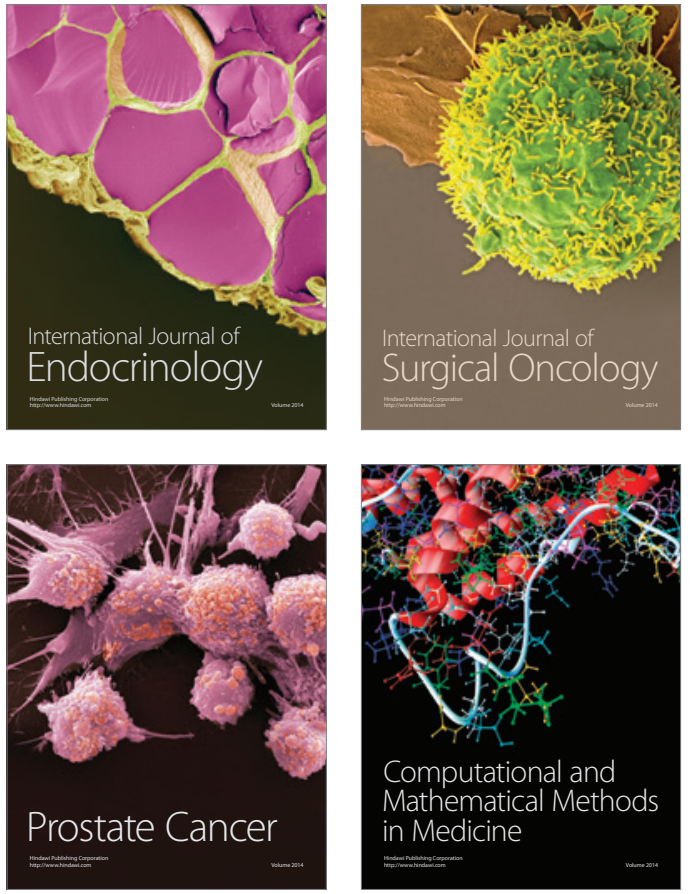
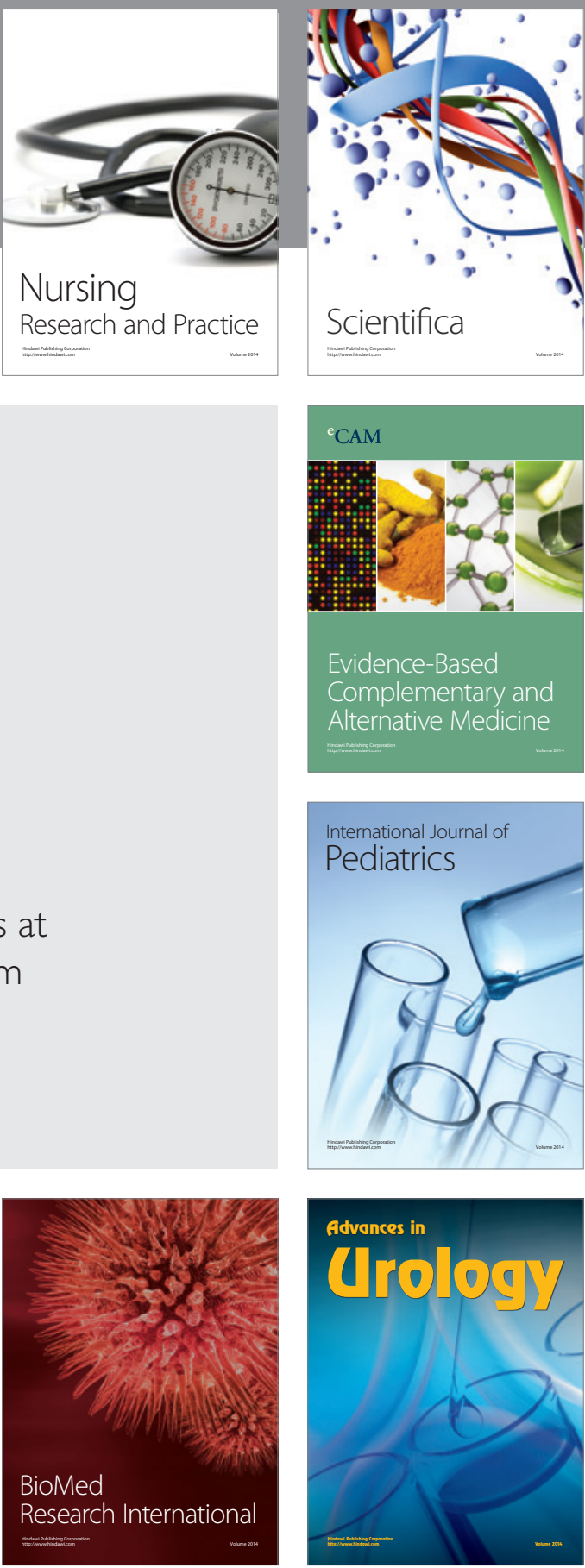

Nursing

Research and Practice

Scientifica

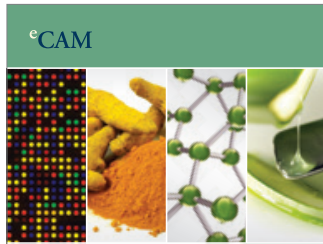

Evidence-Based

Complementary and Alternative Medicine
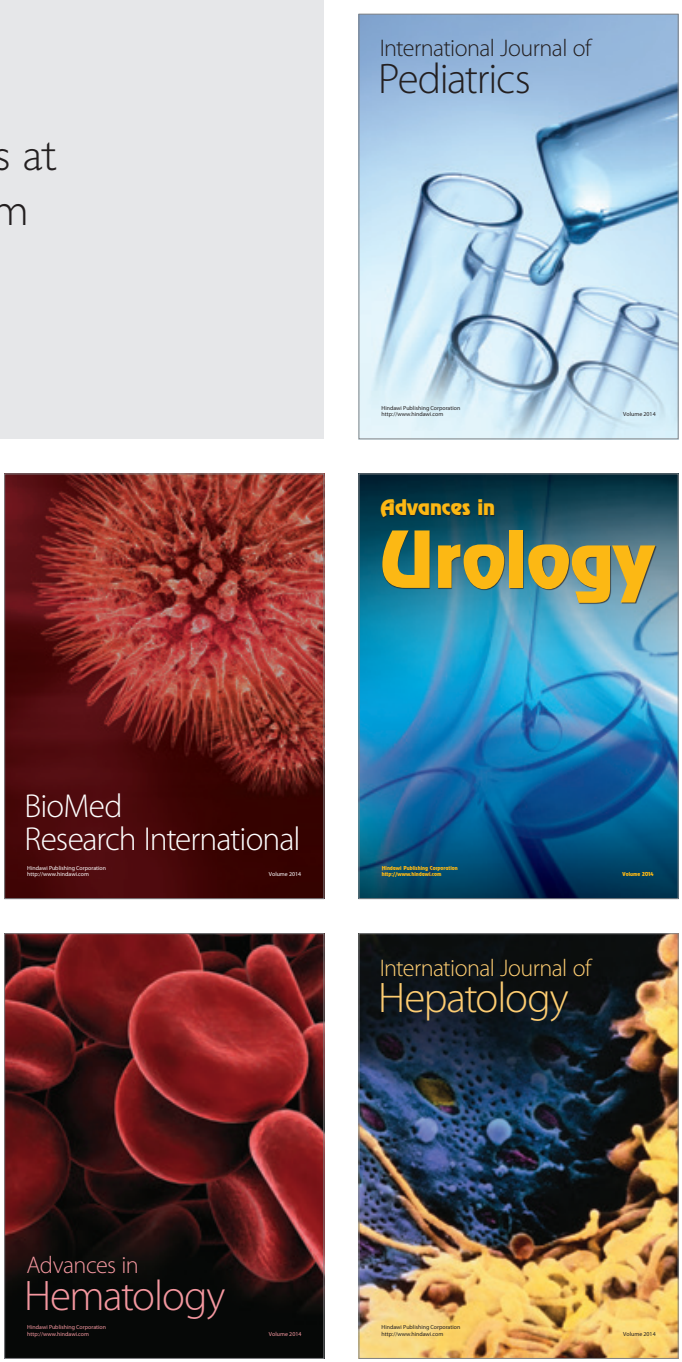